\title{
An Open Letter to the Sleep and Circadian Rhythms Community: Presidents' Viewpoints of the World Sleep Federation (WSF)
}

\author{
Ronald R. Grunstein, MD, PhD'; Clete A. Kushida, MD, PhD² \\ ${ }^{1}$ Immediate Past President, World Sleep Federation and Professor of Sleep Medicine, University of Sydney, Sydney, Australia; ${ }^{2}$ President, World Sleep \\ Federation and Professor of Psychiatry and Behavioral Sciences, Stanford University, Stanford, CA
}

The World Sleep Federation (WSF) is an international organization that was founded in 1988 and is currently comprised of seven Charter members (American Academy of Sleep Medicine, Asian Sleep Research Society, Australasian Sleep Association, Canadian Sleep Society, European Sleep Research Society, Federation of Latin American Sleep Societies, and Sleep Research Society) representing about 53 sleep societies and organizations, and over 12,000 individual members.

\section{Immediate Past President's Viewpoint}

The Scottish polymath, Sir Patrick Geddes who, amongst other things, was a pioneer sexologist, urban planner of places like North Tel Aviv and Bombay, and an early environmentalist coined the phrase "Think Global, Act Local." His concepts emphasized the importance of local "grassroots" activities needing to consider larger or even global impacts of their actions. However, even Geddes would have not foreseen the globalized Internet driven world, with rapid communications and cheap travel across continents. Local actions spread and influence globally so that Geddes' phrase is now "ACT LOCAL AND GLOBAL."

In the world of sleep, we have a great deal to learn from each other and a need to share resources. Our local societies need international structures to permit effective linkages. We have common needs in advocacy to governments and communication to scientists, clinicians, and the public. Even a cursory examination of the approach and effectiveness of organizations such as the International Association for the Study of Obesity (IASO) shows that our field has some way to go in its global presence. ${ }^{2}$ IASO over the past 20 years has focused on global ways of dealing with a major public health problem and provides a potential guide to our activities in dealing with sleep loss across the world. The IASO group provides a forum for both regional and national obesity groups at all levels of science irrespective of professional discipline as well as an International Obesity Task Force that acts as a powerful advocacy arm. ${ }^{3}$

Over the past 4 years, the WSF executive has focused on using limited resources to form a stable international structure and establish special interest groups in key areas of sleep genetics, insomnia, and sleep and breathing. We have held successful

\section{Submitted for publication August, 2012}

Accepted for publication August, 2012

Address correspondence to: Clete A Kushida, MD, PhD, RST, RPSGT, FAASM, Stanford Sleep Medicine Center, 450 Broadway Street, MC 5704, Pavillion C, 2nd Floor, Redwood City, CA 94063; Tel: (650) 7217560; Fax: (650) 721-3465; E-mail: clete@stanford.edu international meetings in Cairns, Australia, and Kyoto, Japan. Moving forward, I have foreshadowed the need for our own international advocacy task force. Bodies such as the World Health Organization (WHO) seek evidence-based guidelines in managing sleep problems in many of the world's emerging economies as part of a strategy in dealing with non-communicable diseases. Only a world-based organization can provide these materials as well as consensus documents on managing sleep loss in the modern world.

One troubling aspect of the sleep field over the past 10 years has been the difficulties of getting all organizations focused on sleep issues to coordinate activities and avoid multiple campaigns and conferences. The WSF is seeking to change thishopefully in partnership with other groups. Our field cannot sustain virtually contemporaneous conferences or duplication of advocacy programs. Nor can our field function properly with isolationist attitudes. Much of the structural work over the past 4 years will bear fruit both with successful prosecution of the agenda as outlined below by Dr. Kushida and a willingness to simultaneously act both locally in our national and regional societies and globally in our international representative group, the WSF.

\section{Current President's Viewpoint}

No matter what country we reside in, we have a personal and national responsibility to be good neighbors and citizens of the world. Increased technology and social networking has had the positive effect of minimizing international barriers and shrinking our world, but there continue to be crises that impact and test our global population, including natural disasters such as the earthquakes in Japan, Chile, and Haiti, and man-made problems such as the recession and global warming. History and experience has taught us that we must pull together, enhance communication, and share resources to collectively overcome such crises. In parallel to these changes affecting our global community and the lessons learned from them, we need to share ideas and programs with our international colleagues and to increase availability of educational and technological resources to those in other countries in order to move our field forward and to increase the likelihood of its viability in the challenging years ahead. This last point underscores the continuing need for a world sleep organization. This need is currently unmet by any sole national sleep organization, since the primary responsibility of any organization is to its membership, and no one national organization has international representation comparable to that of the WSF. In order to ensure this international representation, the current WSF Executive Council is comprised of Vice President Derk Jan-Dijk, MSc, PhD (United Kingdom), 
Secretary General Ning Hung Chen, MD (Taiwan), Treasurer Glenn Legault, PhD (Canada), Training and Education Chair Terri Weaver, PhD, RN (USA), Membership Chair Colin Espie, PhD, MAppSci (Scotland), International Program Co-Chairs Yuichi Inoue, MD, PhD (Japan), Matthew Naughton, MBBS, MD (Australia), and Sean Drummond, PhD (USA), Local Organizing Chair Philippe Peigneux, PhD (Belgium), and Assistant Secretary Hiroshi Kadotani, MD, PhD (Japan). Immediate Past President Ron Grunstein, MD, PhD, and Executive Officer Anthony Williams will also be instrumental in helping to guide the WSF.

In addition to working diligently to support the WorldSleep 2015 Organizing Committee, my three main priorities during my term as WSF president all start with the letter "I":

The first "I" is Infrastructure, and the aim is to further develop the support structure and financial base of the WSF, since any organization, especially a world federation, needs to have a solid foundation to support its various programs and initiatives.

The second "I" is Informatics, with the plan of developing collaborations and sharing of informatics systems and tools (e.g., computer programs, applications, databases, registries) among sleep researchers and clinicians in different nations. Through my personal experiences as principal investigator of the NHLBI-supported Apnea Positive Pressure Long-Term Efficacy Study (APPLES) and the AHRQ-supported Comparative Outcomes Management with Electronic Data Technology (COMET) Project, I have learned the power of shared informatics systems and tools in allowing diverse teams of investigators to work efficiently and effectively together to accomplish complex, multiple tasks and goals. There are other large sleeprelated observational studies, clinical trials, and comparative effectiveness research that have been or are being conducted in multiple sites within and across national borders. Informatics systems and tools have been developed in association with these studies, and it is important that these resources be shared in order to enhance their scope and usability as well as enabling the accelerated development of further informatics systems and tools built upon prior work.

The last "I" is an initiative that I am particularly passionate about, which is Increasing sleep education and training opportunities throughout the world. The plan is to develop educational materials and international certification programs for sleep specialists and technicians, in particular for those individuals in developing countries. At the request of our international colleagues, during my tenure as president of the American Academy of Sleep Medicine (AASM), our AASM Board launched a pilot program to provide board certification tools for international sleep specialists. This initiative allowed countries that did not have sleep medicine board certification programs to establish them within their respective countries. The program was initiated in eight countries (Canada, China, Hong Kong, India, Korea, Taiwan, Thailand, and Turkey) and led to the formation of board certification committees in each of these countries; these committees have either conducted or are planning their first examinations. These types of programs are critical, for as a world organization, we need to work together to meet the needs of our international sleep specialists and to help foster sleep technology throughout the world.

It is important to note that the need for two separate international sleep organizations (WSF and World Association of Sleep Medicine [WASM]) with similar goals may become increasingly less important in the future, and the leadership of both organizations are exploring the possibility of merging the two organizations.

In conclusion, globally facilitating sleep training and research, which may lead to discoveries that uncover the fundamental value of healthy sleep and yield tools resulting in the early identification and management of sleep disorders are key priorities. There are many shared international challenges that lie ahead for our field, including decreasing reimbursement of sleep health services, changing sleep clinical delivery models, increasing technological developments, accommodating rapid growth of sleep centers, the shortage of sleep technicians, adopting international standards for the practice of sleep medicine, and enhancing educational and training opportunities for sleep specialists. Overcoming these challenges will require increased collaborative efforts among countries, yet despite these challenges, the field of sleep medicine and research throughout the world continues to have a bright future. The leadership of the WSF will do its best to ensure and safeguard this precious future.

\section{CITATION}

Runstein RR; Kushida CA. An open letter to the sleep and circadian rhythms community: presidents' viewpoints of the World Sleep Federation (WSF). SLEEP 2012;35(10):1321-1322.

\section{DISCLOSURE STATEMENT}

The authors have indicated no financial conflicts of interest.

\section{REFERENCES}

1. Meller H. Patrick Geddes, social evolutionist and city planner. Routledge, 1990.

2. International Association for the Study of Obesity http://www.iaso.org/

3. International Obesity Task Force http://www.iaso.org/iotf/ 